\title{
RELATIONSHIP BETWEEN TACROLIMUS ORAL DOSE AND ADULT HEART ALLOGRAFT RECIPIENT GENOTYPE
}

\author{
MILAN JUHAS ${ }^{1 *}$, MICHAL KOLORZ ${ }^{2}$ and JIRI VITOVEC ${ }^{3}$ \\ 'Department of Clinical Pharmacy, St. Anne`s University Hospital, \\ Pekarska 664/53, 60200 Brno, Czech Republic \\ ${ }^{2}$ Clinic of Pneumology and Phthisiology, University Hospital in Martin, \\ Kollarova 4248/2, 03601 Martin, Slovak Republic
}

${ }^{3}$ First Department of Internal Medicine-Cardioangiology, St. Anne`s University Hospital, Pekarska 664/53, 60200 Brno, Czech Republic

\begin{abstract}
Determination patient genotype in selected ABCB, p450 CYP3A polymorphisms and their potential phenotypic manifestation in measured tacrolimus level in relation oral dose. 35 adult patients after heart transplantation with immunosuppressant regimen containing oral tacrolimus, mycophenolate mofetil and corticosteroids were eligible. Patient weight, tacrolimus level and dose were collected retrospectively. DNA isolated from buccal smear was tested for presence of $1236 \mathrm{C} \rightarrow \mathrm{T}$ (rs 1128503), 2677G $\rightarrow \mathrm{T} / \mathrm{A}(\mathrm{rs} 2032582), 3435 \mathrm{C} \rightarrow \mathrm{T}$ $(\mathrm{rs} 1045642)$ on $\mathrm{ABCB}$ gene, $1508 \mathrm{C} \rightarrow \mathrm{T}(\mathrm{rs} 1057868)$ on POR gene, 522-191 $\mathrm{C} \rightarrow \mathrm{T}(\mathrm{rs} 35599367)$ on CYP3A4 (CYP3A4*22) and $6986 \mathrm{~A} \rightarrow \mathrm{G}(\mathrm{rs} 776746)$ on CYP3A5 (CYP3A5*3) gene. Statistical analysis was conducted by Chi-square test, statistical significance confirmed if $\mathrm{p}<0.05$. Variant allele frequency in $\mathrm{ABCB}$ tested polymorphisms as follows: 0.53 (3435T), 0.4 (1236T) and 0.4 (2677TA). POR 1508T, CYP3A4*22 and CYP3A5*3 variant allele frequency was $0.27,0.07$ and 0 respectively. ABCB G2677T/A heterozygotes $(83 \% ; n=10)$ required tacrolimus oral dose above $0.075 \mathrm{mg} / \mathrm{kg} / \mathrm{day}$ more often to reach level above $15 \mathrm{ng} / \mathrm{mL}$ in comparison to wild type homozygotes $(\mathrm{p}=0.0263)$. Five patients out of six with tacrolimus level above $15 \mathrm{ng} / \mathrm{mL}$ with 2677GG genotype required tacrolimus dose below $0.075 \mathrm{mg} / \mathrm{kg} /$ day in comparison to variant allele carriers, who needed tacrolimus dose above $0.075 \mathrm{mg} / \mathrm{kg} /$ day $(\mathrm{p}=0.0464)$. Wild type ABCB haplotype patients $(100 \%$; $\mathrm{n}=3$ ) required dose below $0.075 \mathrm{mg} / \mathrm{kg} /$ day in contrast to one patient $(12.5 \%)$ with heterozygote haplotype ( $\mathrm{p}=0.0474$ ). Patients with wild type genotype $2677 \mathrm{GG}$ required lower oral tacrolimus dose than recommended in comparison to variant allele carriers, who needed higher dose to achieve such level 3 months after surgery.
\end{abstract}

Keywords: tacrolimus, heart transplantation, gene polymorphism

Heart transplantation (HTx) represents one of the last options in the treatment of severe heart failure and it is coupled with life-long administration of immunosuppressants with a specific mechanism of action. The introduction of novel immunosuppressants in the early nineties enhanced survival prognosis for patients after solid organ transplantation. Nowadays commonly used tacrolimus (TAC) acts indirectly through binding to intracellular FKBP (TAC previously known as FK506, thus FK506 binging protein) leading to inhibition of calcineurindependent pro-inflammatory mediators syntheses such as interleukin 2, interleukin 3, and $\gamma$-interferon and inhibits T-cell activation and B-cell proliferation $(1,2)$.
Over the years TAC replaced cyclosporine A (CSA) and became the standard immunosuppressive agent of choice used early after surgery (in our transplant center 4-5 days after HTx) in combination with mycophenolate mofetil (or mycophenolic acid) and corticosteroids. Besides, the absence of some CSA adverse effects in TAC (gingival hyperplasia, hirsutism), lower incidence of hypertension, hyperlipidemia, TAC provides superiority in mortality and biopsy-proven acute rejection $(3,4)$. The narrow therapeutic index of TAC, life-long administration, and high risk of toxicity require precise dosing and blood level monitoring. Monitoring and interpretation of TAC blood level rely on knowledge of pharmacokinetic properties (5), however, it is necessary

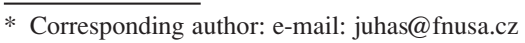


to take in to account inter-individual differences in the variable activity of P-glycoprotein efflux pump in the gut, presystemic and hepatic (cytochromeoxidase P450 CYP3A4 and P450 CYP3A5) enzyme activity (6), which together affect systemic TAC exposure after oral administration. Detailed TAC pharmacokinetic parameters are summarized in Table 1. TAC dosing in HTx differs according to the route of administration: recommended intravenous TAC dose $0.01-0.02 \mathrm{mg} / \mathrm{kg} / \mathrm{day}$ in comparison to oral TAC $0.075 \mathrm{mg} / \mathrm{kg} / \mathrm{day}$ (8) with target whole blood levels according to a specific time after HTx. TAC trough target whole blood levels are summarized in Table 2 and are valid for combination therapy with mycophenolate mofetil or mycophenolic acid.

The aim of this research project was to determine patient genotype in selected $\mathrm{ABCB}$ and CYP polymorphisms. Potential phenotypic manifestation analyzed as measured TAC blood level related to TAC oral dose early after HTx (0-3 months) was also studied. Such data could bring more information necessary for precise TAC dosing in patients in our transplant center and prevent blood level excursions.

\section{EXPERIMENTAL}

This research project was approved by the local ethics committee, patients were explained details of this project and informed consent was obtained before inclusion.

All eligible patients $(n=35)$ were Caucasian, in whom HTx was indicated due to dilated cardiomyopathy (17 males, 2 females), ischemic heart disease (12 males and 1 female), inflammatory cardiomyopathy (1 male), and restrictive cardiomyopathy ( 2 females). The mean age was 55 years in both male and female patients, mean body mass was $82.9 \mathrm{~kg}$.

After HTx, immunosuppression was induced with a therapeutic regimen, which consisted of TAC oral formulation, mycophenolate mofetil and prednisone according to institutional standards. The choice of TAC formulation (Prograf ${ }^{\circledR}$ or Advagraf ${ }^{\circledR}$ ), indication for therapeutic drug monitoring (TDM) and subsequent TAC dosing was based on physician discretion. Patients were instructed to take oral TAC in fasting condition (at least $1 \mathrm{~h}$ before meal) and the whole blood sample for TAC through level measurement was obtained in a steady-state condition. Eligible patients were with stable blood count and no medication with significant drug-drug interactions with TAC noticed.

For purpose of gene polymorphisms analysis, a total genome DNA was isolated from the buccal smear of enrolled patients. Patient actual weight, TAC daily dose and TAC blood levels were collected for retrospective analysis. All patients were tested for the presence of polymorphisms $1236 \mathrm{C} \rightarrow \mathrm{T}(\mathrm{rs} 1128503)$, $2677 \mathrm{G} \rightarrow \mathrm{T} / \mathrm{A}(\mathrm{rs} 2032582), 3435 \mathrm{C} \rightarrow \mathrm{T}(\mathrm{rs} 1045642)$ on $\mathrm{ABCB}$ gene, $1508 \mathrm{C} \rightarrow \mathrm{T}$ (rs1057868) on POR gene, $522-191 \mathrm{C} \rightarrow \mathrm{T}(\mathrm{rs} 35599367)$ on $\mathrm{CYP} 3 \mathrm{~A} 4$ $(\mathrm{CYP} 3 \mathrm{~A} 4 * 22)$ and $6986 \mathrm{~A} \rightarrow \mathrm{G}(\mathrm{rs} 776746)$ on CYP3A5 (CYP3A5*3) gene. The complementary sequences of the primers and probes, and the restriction endonucleases, are listed in Table 3. PCR was performed in $20 \mu \mathrm{L}$ by use of PTC-200 thermocyclers (Bio-Rad). The amplified fragment of DNA was subsequently digested by suitable restriction

Table 1. Tacrolimus pharmacokinetic parameters in adult heart transplant recipients (modified according to ref. 7).

\begin{tabular}{|c|c|}
\hline Bioavailability [\%] & $25(5-93)$ \\
\hline Distribution volume [L/kg] & $1.13-1.69$ \\
\hline Metabolism and elimination & $\begin{array}{c}\text { Hydroxylation via CYP3A4 (major) and CYP3A5, conjugation } \\
\text { to glucuronides and bile elimination }\end{array}$ \\
\hline Clearance $[\mathrm{L} / \mathrm{h} / \mathrm{kg}]$ & $0.19-0.23$ \\
\hline Mean half-life $[\mathrm{hrs}]$ & $10.9(4-14)$ \\
\hline
\end{tabular}

Table 2. Recommended tacrolimus trough whole blood levels in HTx (modified according to ref.: 9, 10).

\begin{tabular}{|c|c|}
\hline Time since HTx [months] & Target level [ng/mL] \\
\hline $0-3$ & $10-15(15-20$ in positive crossmatch $)$ \\
\hline $4-6$ & $8-12(15-20$ in positive crossmatch $)$ \\
\hline 7 and further & $5-10(10-15$ in positive crossmatch $)$ \\
\hline
\end{tabular}




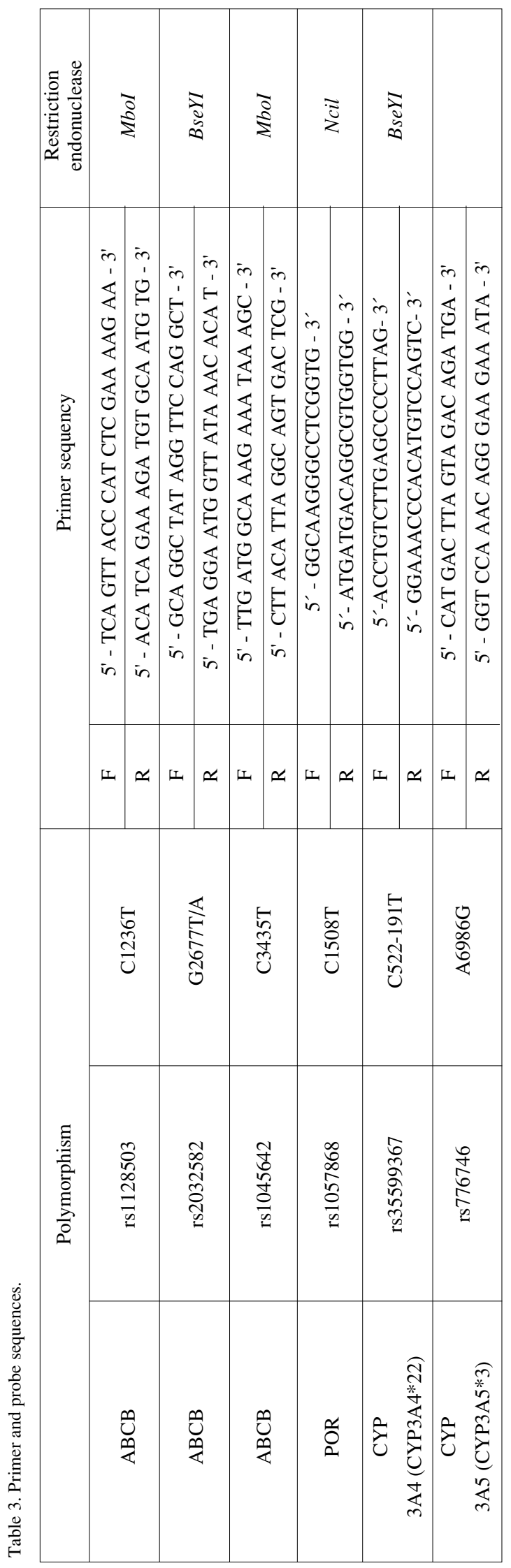


endonucleases (New England Biolabs) and separated by electrophoresis in $2.5 \%$ agarose gel containing ethidium bromide $(0.15 \mathrm{mg} / \mathrm{mL})$. Visualization was performed on the UV transilluminator by the use of $312 \mathrm{~nm}$ light. An allelic variant of the CYP3A5 gene wasThe statistical significance of the acquired data was evaluated by the Chi-square test (GraphPad Prism 7), results were considered statistically significant if $\mathrm{p}<0.05$.

\section{RESULTS AND DISCUSSION}

An allelic variant of previously mentioned polymorphisms was determined in our patient group $(\mathrm{n}=35)$. Among ABCB polymorphisms tested, the highest frequency of variant alleles was found in $3435 \mathrm{~T}$ (0.53), followed by $1236 \mathrm{~T}$ and $2677 \mathrm{~T} / \mathrm{A}$ (both 0.4). Four patients were homozygous for POR $1508 \mathrm{~T}$ variant allele (frequency 0.27 ). Cytochrome CYP3A4*22 variant allele was determined with the lowest frequency (0.07) with none homozygote for variant allele found in our study sample. All patients were homozygous for the standard allele of CYP3A5*3. Genotypes distribution and variant allele frequencies are summarized in Table 4.

Twenty-two (63\%) out of all enrolled patients achieved TAC blood level above $15 \mathrm{ng} / \mathrm{mL}$ within the first three months after HTx. Five (14\% of total enrolled) out of 6 patients with ABCB 2677GG genotype reached TAC therapeutic level above 15 $\mathrm{ng} / \mathrm{mL}$ with a dose below $0.075 \mathrm{mg} / \mathrm{kg} / \mathrm{day}$. There were 12 patients G2677T/A heterozygotes detected in our study group. Majority of heterozygotes (83\%, $\mathrm{n}=10$ ) on this polymorphism required TAC oral dose above $0.075 \mathrm{mg} / \mathrm{kg} /$ day. Heterozygosity on this polymorphism was associated with the need of TAC oral dose higher than $0.075 \mathrm{mg} / \mathrm{kg} /$ day to reach blood level above $15 \mathrm{ng} / \mathrm{mL}$ in comparison to wild type homozygosity $(\mathrm{p}=0.0263)$.
Among patients, who reached this TAC blood level above $15 \mathrm{ng} / \mathrm{mL}(\mathrm{n}=22)$, overall 6 patients were determined as $2677 \mathrm{GG}$ genotype. Five out of these six patients took TAC dose below $0.075 \mathrm{mg} / \mathrm{kg} /$ day in contrast with variant allele carriers $(\mathrm{n}=16)$, who more often required dose above $0.075 \mathrm{mg} / \mathrm{kg} /$ day to reach the target level, thus the presence of variant allele of ABCB G2677T/A was associated with the need of higher daily TAC dose $(\mathrm{p}=0.0464)$.

All patients $(100 \% ; \mathrm{n}=3)$ with wild type $\mathrm{ABCB}$ haplotype required TAC oral dose below 0.075 $\mathrm{mg} / \mathrm{kg} /$ day to reach TAC blood level above 15 $\mathrm{ng} / \mathrm{mL}$ in first three months after HTx. In contrast only one patient with heterozygote $\mathrm{ABCB}$ haplotype $(12.5 \% ; \mathrm{n}=1)$ reached TAC blood level above 15 $\mathrm{ng} / \mathrm{mL}$ with same dose $(\mathrm{p}=0.0474)$.

Although a lack of statistical significance, our further results provide some noteworthy tendencies. A major proportion of patients with $\mathrm{ABCB} 1236 \mathrm{CC}$ genotype $(71 \% ; n=5)$ required TAC daily dose below $0.075 \mathrm{mg} / \mathrm{kg} /$ day when compared to individuals with variant allele of this polymorphism (heterozygote and variant homozygote together $(29 \%$; $\mathrm{n}=4)$ ).

All patients with $\mathrm{ABCB}$ wild type haplotype reached TAC blood level above $15 \mathrm{ng} / \mathrm{mL}$ with TAC dose below $0.075 \mathrm{mg} / \mathrm{kg} /$ day in comparison to heterozygote and variant haplotype combined (100\%; $\mathrm{n}=3$ vs $25 \%$; $\mathrm{n}=3$ ).

We also observed, that regardless of TAC dose, variant $\mathrm{ABCB}$ genotype was often present among patients with TAC level above $15 \mathrm{ng} / \mathrm{mL}$. According to patient genotype this target was achieved in $83 \%$ of $\mathrm{ABCB} 1236 \mathrm{TT}(\mathrm{n}=5), 63 \%$ $(\mathrm{n}=10) 1236 \mathrm{CT}$ and $53 \%(\mathrm{n}=7)$ of $1236 \mathrm{CC}$ carriers. Similar results were obtained for ABCB 2677 polymorphism, where wild type homozygote genotype was present in 50\% $(\mathrm{n}=6)$ of patients with TAC level above $15 \mathrm{ng} / \mathrm{mL}$ in comparison to $67 \%$

Table 4. Patient numbers and variant allele frequency.

\begin{tabular}{|c|c|c|c|c|c|c|}
\hline \multicolumn{3}{|c|}{ Polymorphism } & Homozygote wild & Heterozygote & Homozygote & Variant allele \\
\hline $\mathrm{ABCB}$ & rs1128503 & $\mathrm{C} 1236 \mathrm{~T}$ & 13 & 16 & 6 & 0.40 \\
\hline $\mathrm{ABCB}$ & rs2032582 & G2677T/A & 12 & 18 & 5 & 0.40 \\
\hline $\mathrm{ABCB}$ & rs1045642 & C3435T & 7 & 19 & 9 & 0.53 \\
\hline POR & rs1057868 & $\mathrm{C} 1508 \mathrm{~T}$ & 20 & 11 & 4 & 0.27 \\
\hline $\begin{array}{c}\text { CYP3A4 } \\
(\mathrm{CYP} 3 \mathrm{~A} 4 * 22)\end{array}$ & rs35599367 & C522-191T & 30 & 5 & 0 & 0.07 \\
\hline $\begin{array}{c}\text { CYP3A5 } \\
(\mathrm{CYP} 3 \mathrm{~A} 5 * 3)\end{array}$ & rs776746 & A6986G & 35 & 0 & 0 & 0.00 \\
\hline
\end{tabular}


( $n=12)$ of heterozygotes and $80 \%(n=4)$ of variant allele homozygotes. In addition, $\mathrm{ABCB}$ variant haplotype was most common $(80 \%, \mathrm{n}=4)$ in patients, who reached therapeutic level in comparison to heterozygote $(62 \%, \mathrm{n}=8)$ and wild type individuals $(43 \%, \mathrm{n}=3)$.

According to available data from the International Society of heart and lung transplantation (ISHLT), 1 and 5-year survival rate after HTx has improved since the 1980 s from $76.9 \%$ and $62.7 \%$ to $84.5 \%$ and $72.5 \%$ in $2002-2012$ period (11). Undoubtedly, the immunosuppression regimen containing calcineurin inhibitors (CNI) has contributed to this improvement.

With respect to the TAC narrow therapeutic window, it is absolutely crucial to maintain optimal drug levels to achieve sufficient immunosuppressive activity and also to avoid serious adverse effects. TDM represents the method of choice for monitoring patient-tailored proprietary dosing and therapy maintenance. Besides predictable factors influencing TAC pharmacokinetics such as disease state, concomitant medication and functionality of elimination organs, genome-associated factors could potentially contribute to inter-individual variability. Pharmacogenomics studies focus on describing gene polymorphisms with potential therapeutic predicting value. For example, knowledge of genebased determinants could predict groups of patients with need of drug doses, that significantly differs from major population. Well-controlled TAC level and precise dosing with taking into account patient genome differences can help prevent drug-related complications and improve patient outcomes.

This study focused on polymorphism genotyping on P-glycoprotein (ABCB gene) and cytochrome $\mathrm{P} 450$ gene in HTx patients. Allelic variants of selected polymorphisms were determined in 35 patients. TAC oral doses necessary to achieve therapeutic levels above $15 \mathrm{ng} / \mathrm{mL}$ within three months after HTx were retrospectively analyzed in groups of patients with a different genotype.

P-glycoprotein, a product of $\mathrm{ABCB}$ gene expression, is one of the most important efflux systems of xenobiotics in humans. Its activity influences the bioavailability of the drug after oral intake. Several gene polymorphisms on the ABCB gene are believed to influence P-glycoprotein activity (phenotype), between them C1236T, G2677T/A and C3435T affect efflux capacity (12). In our population sample among $\mathrm{ABCB}$ gene polymorphisms tested, the highest frequency of variant alleles was found in $3435 \mathrm{~T}$ (0.53), followed by $1236 \mathrm{~T}$ and 2677TA (both 0.40). It confirms the high presence of variant alleles in the Caucasian population (13). Our results showed, that in the first three months after HTx, patients with ABCB 2677T/A genotype more often required TAC oral dose above the recommended $0.075 \mathrm{mg} / \mathrm{kg} /$ day. Heterozygosity on this polymorphism was associated with the need for a higher TAC oral dose than recommended to reach a blood level above $15 \mathrm{ng} / \mathrm{mL}$ in comparison to wild type homozygosity $(\mathrm{p}=0.0263)$. Among patients who reached this TAC blood level $(n=22)$, overall 6 patients were determined as $2677 \mathrm{GG}$ genotype. Five of these patients took dose below 0.075 $\mathrm{mg} / \mathrm{kg} /$ day, thus the presence of variant allele of $\mathrm{ABCB}$ (heterozygote or variant homozygote) was associated with the need for a higher daily TAC dose $(\mathrm{p}=0.0464)$.

Similarly, a major proportion of patients with $\mathrm{ABCB} 1236 \mathrm{CC}$ genotype $(71 \%, \mathrm{n}=5)$ required TAC daily dose below $0.075 \mathrm{mg} / \mathrm{kg} /$ day when compared to individuals with a variant allele of this polymorphism (heterozygote and variant homozygote together $(29 \%$; $n=4)$ ), however, these results did not reach statistical significance.

TAC blood level above $15 \mathrm{ng} / \mathrm{mL}$ was also achieved with doses below $0.075 \mathrm{mg} / \mathrm{kg} /$ day in all patients $(n=3)$ with $\mathrm{ABCB}$ wild type haplotype in contrast to only one patient with ABCB heterozygous haplotype group $(12.5 \%)(p=0.0474)$. These findings point out a possibility, that variant allele presence increases P-glycoprotein efflux capacity, which leads to increased TAC oral consumption in comparison to wild type ABCB patients.

A study conducted on 6 TAC (oral dose 0.075 $\mathrm{mg} / \mathrm{kg} /$ day) treated patients after HTx concluded, that patients with a variant allele in ABCB reached significantly higher TAC blood level in the first 2 weeks post-transplantation than wild type population (14). However, data in adult HTx patients are scarce and if available, they are inconclusive.

Data available in renal transplant recipients provide different findings. The presence of variant allele - homozygotes was coupled with a lower TAC dose required in comparison to wild type genotype (15) suggesting lower efflux P-glycoprotein activity in variant allele homozygotes. This study contained not only Caucasian population (2677GG; $\mathrm{n}=37$ ), but also significant portion of black patients (2677GG; $\mathrm{n}=24$ ).

Another study, which contained $41 \mathrm{ABCB}$ G2677T/A heterozygote patients ( 73 white, 7 black, and 1 Indian) after renal transplantation concluded, that heterozygotes required lower TAC oral dose in comparison to wild type genotype (16). TAC blood level in this study could be affected by concomitant 
medication since investigators did not exclude patients with a medication known for drug-drug interaction with TAC.

Another possible source of differences between our results and other studies conducted on patients after kidney transplantation is, that TAC pharmacokinetic properties differ in solid organ transplantation (17).

There were four patients-homozygotes for POR 1508T variant allele in our study group, five patients were tested as heterozygotes in CYP3A4*22. There were no patients detected as variant allele homozygotes in CYP3A4*22 and CYP3A $5 * 3$ in our study group.

NADPH:cytochrome P450 oxidoreductase (POR) is essential for cytochrome P450 monooxygenase $3 \mathrm{~A}$ and its role consists of electron transfer to iron component of P450 prosthetic heme (18). Cytochromeoxidase $\mathrm{P} 450$ 3A4 and 3A5 have a major role together with $\mathrm{P}$-glycoprotein in presystemic and hepatic TAC metabolism, which results in the formation of metabolites without immunosuppressive activity and are substrates for conjugation reactions prior to their excretion $(19,20)$.

There are data on tacrolimus pharmacokinetics in HTx, where CYP3A5 expressors required 2.2 to 2.6 higher TAC oral dose in comparison to nonexpressors, furthermore the proportion of $\mathrm{POR} * 28$ effect in CYP3A5 expressors had an additional effect in higher TAC dose adjusted-concentrations within first 3 and 6 months after HTx (21).

Combined effect of CYP3A $4 * 22$ and CYP3A5*3 genotypes was studied in patients after HTx $(\mathrm{n}=74)$, where CYP3A5*3 homozygotes $(\mathrm{n}=$ 59 ) had $67 \%$ higher mean dose-adjusted TAC level than CYP3A5*1 carriers $(n=15)$. Evaluation of combined effect of CYP3A $4 * 22$ and CYP3A5 resulted in $77 \%$ higher mean dose-adjusted TAC level in poor metabolizers (CYP3A4*22+ CYP3A $5 * 3 / * 3$ carriers) in comparison to extensive metabolizers (CYP3A4*1/*1+CYP3A5*1 carriers) and $63 \%$ higher in intermediate metabolizers (CYP3A4*1/*1+CYP3A $5 * 3 / * 3$ carriers) in comparison to extensive metabolizers (22).

A study conducted on 76 patients $(81.6 \%$ Caucasian population) after HTx confirmed the key role of CYP3A5 expression at the expense of CYP3A4. The dose-adjusted TAC level did not differ between CYP3A4*22 genotypes. CYP3A5 expressers had a 1.8 -fold lower dose-adjusted TAC level in comparison to non-expressers and this result was not different when combined genotype $($ CYP3A4*22 + CYP3A5*3) was analyzed (23).

There were no statistically significant differences in
TAC blood levels and TAC dosing in our group of patients with the following polymorphisms: $\mathrm{ABCB}$ C1236T (rs1128503), ABCB C3435T (rs1045642), C1508T (rs1057868) on POR gene and C522-191T (rs35599367) on CYP3A4 (CYP3A4*22) found. All patients were tested wild type in A6986G (rs776746) on CYP3A5 (CYP3A5*3) gene.

\section{CONCLUSION}

It turns out, that in the early period after HTx, patients with wild type genotype ABCB 2677GG require a lower TAC oral dose than recommended $0.075 \mathrm{mg} / \mathrm{kg} /$ day in comparison to variant allele carriers, who need a higher TAC dose to reach the desired TAC blood level. Further studies with a larger number of patients are required to confirm.

\section{Acknowledgments}

This work was supported by IGA VFU Brno grant 305/2015/FaF.

\section{Conflict of interest statement}

The authors state that there are no conflicts of interest regarding the publication of this article.

\section{REFERENCES}

1. Thomson A.W., Bonham C.A., Zeevi A.: Ther. Drug Monit. 17, 584 (1995).

2. Schreiber S.L., Grabtree G.R.: Immunol. Today 13, 136 (1992).

3. Penninga L., Mřller C.H., Gustafsson F.: Eur. J. Clin. Pharmacol. 66, 1177 (2010).

4. Guethoff S., Meiser B.M., Groetzner J., Eifert S., Grinninger C., et al.: Transplantation 95, 629 (2013).

5. Venkataramanan R., Swaminathan A., Prasad T., Jain A., Zuckerman S., et al.: Clin. Pharmacokinet. 29, 404 (1995).

6. Staatz C.E., Goodman L.K., Tett S.E.: Clin. Pharmacokinet. 49, 207 (2010).

7. McCormack P.L., Keating G.M.: Drugs 66, 2269 (2006).

8. SPC Prograf Astellas Pharma, Praha, Czech Republic, 14.2.2019.

9. Taylor D.O., Barr M.L., Meiser B.M., Pham S.M., Mentzer R.M., Gass A.L.: J. Heart Lung Transplant. 20, 734 (2001).

10. https://www.ikem.cz/UserFiles/article/files/ 1444804138metodicke-postupy-transplantacesrdce.pdf (accessed on 17.12.2019). 
11. Lund L.H., Edwards L.B., Kucheryavaya A.Y., Bended C., Christie J.D., et al.: J. Heart Lung Transplant. 33, 996 (2014).

12. Barbarino J.M., Staatz C.E., Venkataramanan R., Klein T.E., Altman R.B.: Pharmacogenet. Genomics 23, 563 (2013).

13. Staatz C.E., Goodman L.K., Tett S.E.: Clin. Pharmacokinet. 49, 141 (2010).

14. Herrero M.J., Almenar L., Jordán C., Sánchez I., Poveda J.L., Aliňo S.F.: Transpl. P. 42(8), 3181 (2010).

15. Fredericks S., Moreton M., Reboux S., Carter N.D., Goldberg L., Holt D.W., MacPhee I.A.M.: Transplantation 82(5), 705 (2006).

16. Anglicheau D., Verstuyft C., Laurent-Puig P., Becquemont L., Schlageter M., Cassinat B., Beaune P., Legendre C., Thervet E.: J. Am. Soc. Nephrol. 14(7), 1889 (2003).
17. Staatz C.E., Tett S.E.: Clin. Pharmacokinet. 43, 623 (2004).

18. Zanger U.M., Schwab M.: Pharmacol. Therapeut.138, 103 (2013).

18. Vicari-Christensen M., Repper S., Basile S., Young D.: Prog. Transplant. 19, 277 (2009).

19. Lhoëst G., Verbeek R.K., Maton N., Muthelet P., Latinne D.: J. Pharmacol. Exp. Ther. 274, 622 (1995).

20. Lesche D., Sigurdardottir V., Setoud R., Oberhänsli M., Carrel T., et al.: Ther. Drug. Monit. 36, 710 (2014)

21. Vu A., Page R.L., Roscoe N., Lindenfeld J.A., Aquilante C.L.: J. Heart Lung Transplant. 33, S115 (2014).

22. Deininger K.M., Vu A., Page R.L., Ambardekar A.V., Lindenfeld J., Aquilante C.L.: Clin. Transplant. 30, 1074 (2016). 